\title{
UJI AKTIVITAS ANTIHIPERLIPIDEMIA EKSTRAK ETANOL BUAH PINANG YAKI (Areca vestiaria) PADA TIKUS PUTIH JANTAN GALUR WISTAR (Rattus norvegicus) YANG DIINDUKSI PAKAN HIPERLIPIDEMIA
}

\author{
Steleynes J. J. Sagay ${ }^{1)}$, Herny E. Simbala ${ }^{1)}$, Edwin de Queljoe ${ }^{2)}$ \\ ${ }^{1)}$ Program Studi Farmasi FMIPA UNSRAT Manado, 95115 \\ 2)Jurusan Biologi FMIPA UNSRAT Manado, 95115
}

\begin{abstract}
Pinang Yaki (Areca vestiaria) is a plan originating from the North Sulawesi region. Pinang Yaki nut containds flavonoide which can act as anti-hyperlipidemia. The study aims to identify the antihyperlipidemic actibity of ethanol extract of Pinang Yaki (Areca vestiaria) fruit on wistar strain rats induced by hyperlipidemic. Total cholesterol level is a parameter on this study. The method used was laboratory experimental with a completely randomized design. The result of the study were obtained from 2 stagxes of measuring blood cholesterol, namely pre and post. The treatment was started by giving high-fat feed for 28 days. On the $29^{\text {th }}$ day pre measurementswere taken. Furthermore, treatment was given to each group, namely CMC in the negative control group, simvastatin in the positive control groups, and ethanol extract of Pinang Yaki Fruit with doses of each group of PS2 (200 mg), PS4 (400 mg), and PS8 (800 mg). Post measurement are cerried out after 2 hours of administration. Data were analyzed by Paired T-test. Statistical results indicate a significant difference between the pre and post groups. From the percentage point of view, the dose of $400 \mathrm{mg}$ ethanol extract of Pinang Yaki Fruit gives the best reduction in blood cholesterol level
\end{abstract}

Keywords: Pinang Yaki Fruit, Antihyperlipidemia, Male White Rat.

\begin{abstract}
ABSTRAK
Pinang Yaki (Areca vesitaria) merupakan tanaman yang berasal dari daerah Sulawesi Utara. Buah Pinang Yaki mengandung flavonoid yang dapat berperan sebagai antihiperlipidemia. Penelitian ini bertujuan untuk mengidentifikasi aktifitas antihiperlipidemia Ekstrak etanol buah Pinang Yaki (Areca vestiaria) terhadap tikus galur wistar yang diinduksi hiperlipidemia. Kadar kolesterol total merupakan parameter dalam penelitian ini. Metode yang digunakan eksperimental laboratorium dengan rancangan acak lengkap. Hasil penelitian diperoleh dari 2 tahap pengukuran kolesterol darah, yaitu pre dan post. Perlakuan dimulai dengan memberi pakan tinggi lemak selama 28 hari. Pada hari ke 29 dilakukan pengukuran pre. Selanjutnya diberikan perlakuan pada tiap kelompok, yaitu CMC pada kelompok Kontrol negatif, simvastatin pada kelompok Kontrol positif, dan ekstrak etanol buah pinang yaki dengan dosis masing-masing kelompok PS2 (200 mg), PS4 (400 mg), dan PS8 (800 mg). Pengukuran Post dilakukan setelah 2 jam pemberian. Data dianalisis dengan Paired T-test. Hasil statistika menunjukkan adanya perbedaan yang signifikan antara kelompok pre dan post. dilihat dari presentase, dosis ekstrak etanol buah pinang yaki $400 \mathrm{mg}$ memberikan penurunan kadar kolesterol darah terbaik.
\end{abstract}

Kata kunci : Buah Pinang Yaki, Antihiperlipidemia, Tikus Putih Jantan 


\section{PENDAHULUAN}

Penyakit kardiovaskuler akibat aterosklerosis yaitu plak pada pembuluh arteri koroner jantung yang disebabkan oleh kadar kolesterol yang tinggi, serta merupakan penyebab utama kematian di dunia. Salah satunya adalah penyakit jantung koroner (PJK). Banyak hal yang berperan dalam PJK, diantaranya adalah hiperlipidemia. (Septianggi, 2013).

Hiperlipidemia adalah gangguan pada sistem metabolisme lemak yang menyebabkan peningkatan kadar kolesterol total, LDL, trigliserida darah dan penurunan HDL. Pada umumnya hiperlipidemia dikendalikan dengan diet, olahraga dan terapi obat-obatan dalam hal ini adalah obat sintetik salah satunya simvastatin, yang telah diketahui memiliki efek samping bagi tubuh. seperti miopati, hepatotoksik, neuropati perifer pusing, diare dan alergi (Anwar, 2004).

Pinang yaki merupakan salah satu tumbuhan endemik Sulawesi. Di Sulawesi Utara tanaman tersebut selain tumbuh di kawasan Taman Nasional Bogani Nani Wartabone, pinang yaki (Areca vestiaria G.) juga tumbuh di cagar alam gunung Ambang kabupaten Bolaang Mongondow, cagar alam gunung Tangkoko dua saudara, di lereng G. Soputan dan G. Mahawu kabupaten Minahasa. Tanaman pinang yaki tersebut oleh masyarakat di Bolaang Mongondow yang tinggal dikawasan Taman Nasional Bogani Nani Wartabone digunakan sebagai obat untuk penyakit diabetes dan juga dipakai sebagai obat kontrasepsi. Buah pinang yaki mengandung senyawa-senyawa metabolit sekunder seperti alkaloid, flavonoid, triterpenoid, steroid, dan tanin yang memiliki efek sebagai antifertilisasi (Simbala, 2017). Golongan senyawa flavonoid, saponin, polifenol dan terpenoid yang terkandung di dalam tanaman mampu mengatasi obesitas sebab senyawa tersebut berkontribusi dalam inhibisi enzim lipase pankreatik, sehingga absorbsi trigliserida dalam tubuh akan terhambat (Yamamoto dkk., 2000).

\section{METODOLOGI PENELITIAN}

\section{Waktu dan Tempat Penelitian}

Penelitian ini telah dilaksanakan selama 6 bulan yaitu di mulai dari bulan Oktober sampai bulan April Tahun 2019 di Laboratorium Penelitian Program Studi Farmasi dan Laboratorium Farmakologi Jurusan Biologi Fakultas Matematika dan Ilmu Pengetahuan Alam, Universitas Sam Ratulangi, Manado.

\begin{abstract}
Alat
Timbangan analitik, timbangan hewan uji, sudip, cawan petri, ayakan 200 mesh, oven, labu ukur $100 \mathrm{~mL}$, gelas beker, pipet, batang pengaduk, lumpang dan alu, hot plate, kertas saring, sarung tangan lateks merek sensi gloves, masker merek sensi mask, sonde oral, kapas, kandang tikus putih galur wistar, lemari pendingin atau kulkas, alat ukur kolesterol dan strip kolesterol merek AUTOCHECK.
\end{abstract}

\section{Bahan}

Bahan yang digunakan: Tikus putih jantan galur wistar (Rattus novergicus) 15 ekor, ekstrak etanol buah pinang yaki (Areca vestiaria), CMC (carboxymethylcellulose), aquades, etanol $96 \%$, beras jagung, kuning telur ayam, simvastatin $10 \mathrm{mg}$, aquades, propiltiourasil (PTU) $100 \mathrm{mg}$. 


\section{Prosedur Penelitian}

\section{Penyiapan Hewan Uji}

Penelitian ini menggunakan Tikus putih jantan galur wistar (Rattus norvegicus) sebagai hewan uji yang dibagi secara acak menjadi 5 kelompok dimana masing-masing kelompok terdiri atas 3 ekor. Tikus diaklimatisasikan terlebih dahulu selama 7 hari, agar terbiasa dengan kondisi laboratorium. Selama masa aklimatisasi, tikus diberikan pakan beras jagung dan air minum ad libitium.

\section{Penyiapan Pakan Hiperlipidemia}

Makanan hiperlipidemia menggunakan kuning telur ayam mentah dan larutan PTU. Terlebih dahulu dipisahkan kuning telur dari bagian putih telur, dan kemudian dikocok sampai kuning telur menjadi lebih encer. Volume administrasi oral yang diberikan adalah $1 \mathrm{~mL} /$ tikus/hari.

Dosis rentang PTU untuk orang dewasa adalah 500-2.000 mg. Dosis yang digunakan dalam penelitian ini ialah $2.000 \mathrm{mg}$. Dosis yang digunakan pada tikus dengan berat rata-rata 180 g yaitu: $180 / 50.000$ x $2.000=7 \mathrm{mg} /$ tikus/hari . PTU dibuat dalam bentuk larutan dengan cara melarutkan satu tablet $100 \mathrm{mg}$ PTU dalam 14 $\mathrm{mL}$ pelarut (akuades), sehingga dalam $1 \mathrm{ml}$ larutan terkandung 7 mg PTU (Suhendra,2016)

\section{Pemberian Pakan Hiperlipidemia pada Hewan Uji}

Hewan uji dipegang dengan cara menempatkan tangan di sekitar dada bagian atas, ibu jari ditempatkan di bawah rahang hewan tetapi tidak memberikan tekanan pada tenggorokan. Pakan diberikan melalui rute oral. Sonde oral dimasukan pada langit-langit mulut atas tikus, kemudian perlahan-lahan dimasukan sampai ke esofagus dan pakan diinduksi secara perlahan (Harini, 2009).

\section{Pembuatan Ekstrak Etanol Buah Pinang Yaki}

Ekstraksi dilakukan dengan metode ekstraksi dingin yaitu maserasi mengguanakan pelarut etanol 96\%. Buah Pinang Yaki yang telah menjadi serbuk simplisia ditimbang dan dimasukkan ke dalam beker gelas kemudian diekstraksi dengan cara serbuk simplisia direndam dalam pelarut etanol 96\%, dan dibiarkan selama 5 hari, kemudian disaring menggunakan kertas saring. Filtrat yang diperoleh, dipekatkan dengan menggunakan oven pada suhu $40^{\circ} \mathrm{C}$ sampai diperoleh ekstrak kental

\section{Pembuatan Larutan CMC 1\%}

Larutan stok CMC 1\% dibuat dengan menimbang serbuk CMC sebanyak $1 \mathrm{~g}$ kemudian dicampurkan dengan $100 \mathrm{~mL}$ aquades dihomogenkan dengan cara pemanasan menggunakan hot plate, kemudian didinginkan. Perbandingan aquades dengan CMC adalah 100:1 artinya didalam $100 \mathrm{~mL}$ aquades terdapat $1 \mathrm{~g} \mathrm{CMC}$.

\section{Pembuatan Larutan Uji}

Dosis pemakaian buah Pinang yaki (Areca vestiaria) dengan faktor konversi dosis dari manusia $(70 \mathrm{~kg}$ ) ke hewan uji $(200 \mathrm{~g})$ dengan dikalikan 0,018 yaitu 3,6 mg, 7,2 mg, dan 14,4 mg. Ekstrak buah Pinang yaki (Areca vestiaria) ditimbang sesuai dengan dosis $(3,6 \mathrm{~g}$, 7,2 g, dan 14,4 g) disuspensikan dengan larutan CMC $1 \%$ sampai $10 \mathrm{~mL}$ dalam gelas ukur kemudian diaduk hingga homogen. Menurut Deldago (1982), penggunaan CMC tidak akan berpengaruh terhadap perubahan kadar kolesterol total darah karena CMC tidak dicerna dan diabsorpsi oleh tubuh. Setelah homogen, masing-masing dosis ekstrak di masukkan ke dalam botol sampel dan diberi label. PS2 untuk 
ekstrak buah pinang yaki dengan dosis $3,6 \mathrm{mg}$; PS4 untuk ekstrak dosis 7,2 mg; dan PS8 untuk ekstrak dosis $14,4 \mathrm{mg}$.

\section{Pembuatan dan Pemberian Larutan Simvastatin}

Simvastatin $10 \mathrm{mg}$ dilarutkan dengan larutan CMC $1 \%$ sampai $10 \mathrm{~mL}$. Volume administrasi oral yang diberikan sebanyak 1 $\mathrm{mL} / \mathrm{tikus}$. Dosis Simvastatin untuk manusia adalah $10 \mathrm{mg}$, dikonversikan dalam dosis tikus 0,018 didapat $0,18 \mathrm{mg}$. Penentuan dosis Simvastatin adalah sebagai berikut :

$$
\begin{aligned}
& \quad \frac{\text { Berat ditimbang } 20 \text { tablet }}{\text { rata }- \text { rata jumlah tablet }} \\
& \frac{4056 \mathrm{mg}}{20}=202 \mathrm{mg} \\
& \frac{202 \mathrm{mg}}{10 \mathrm{mg}} \times 0,18 \mathrm{mg}=3,636 \mathrm{mg} / \text { tikus } \\
& \frac{3,636 \mathrm{mg}}{1 \mathrm{~mL}} \times 10 \mathrm{~mL}=36,4 \mathrm{mg} / \mathrm{tikus} \\
& \text { Jadi, dalam larutan stok } 10 \mathrm{~mL}, \\
& \text { mengandung 36,4 mg simvastatin, dan setiap } 1 \\
& \mathrm{~mL} \text { mengandung } 3,636 \mathrm{mg} \text { simvastatin }
\end{aligned}
$$

\section{Pengukuran Kadar Kolesterol Total Plasma Darah}

Hewan uji yang telah dikelompokkan dan menerima perlakuan, dilakukan pengamatan berat badan dengan cara menimbang semua hewan uji pada setiap kelompok, dilakukan perminggu yaitu pada hari ke-0, 7, 14, 21, 28. 29. Tikus dipuasakan selama 12 jam, kemudian dibersihkan dengan kapas alcohol pada bagian ekor sehingga kotoran yang terdapat pada ekor tikus dapat dibersihkan (sterilisasi ekor tikus). Selanjutnya darah diambil beberapa tetes pada ekor yang telah dilukai. Pengukuran kadar kolesterol total tikus setiam minggu selama 28 hari +1 hari perlakuan, menggunakan alat ukur kolesterol (AUTOCHECK) dengan kisaran pemeriksaan 100-400 mg/dL.

\section{Teknik Analisa Data}

Data disajikan secara deskriptif komparatif dengan menilai hasil pemeriksaan kadar kolesterol total antara kelompok K-, K+, PS2, PS4, dan PS8, serta dianalisis menggunakan program SPSS v.20 dengan uji Paired T-test untuk melihat perubahan (penurunan) kadar kolesterol darah sebelum dan sesudah perlakuan dengan $\mathrm{p}<0,05$.

\section{HASIL DAN PEMBAHASAN}

Pengaruh Pakan Hiperlipidemia Terhadap

\begin{tabular}{|c|c|c|c|c|c|}
\hline $\begin{array}{l}\text { Kelompok } \\
\text { Perlakuan }\end{array}$ & $\begin{array}{c}\text { He } \\
(\mathrm{mg} / \mathrm{dL})\end{array}$ & $\begin{array}{c}\mathrm{H}^{-} \\
(\mathbf{m g} \mathrm{dL})\end{array}$ & $\begin{array}{c}\mathrm{H} 14 \\
\text { (mg/dL) }\end{array}$ & $\begin{array}{c}\text { H2I } \\
(\mathrm{mg} / \mathrm{dL})\end{array}$ & $\begin{array}{c}\mathrm{H} 28 \\
\text { (mg/dL) }\end{array}$ \\
\hline K- & Lo $(<100)$ & 102 & 104 & 105 & 107 \\
\hline $\mathbf{K}+$ & Lo $(<100)$ & 101 & 103 & 107 & 117 \\
\hline PS2 & Lo $(<100)$ & Lo $(<100)$ & Lo $(<100)$ & 105 & 116 \\
\hline PS4 & Lo $(<100)$ & Lo $(<100)$ & 103 & 108 & 120 \\
\hline PS8 & Lo $(<100)$ & Lo $(<100)$ & Lo $(<100)$ & 105 & 118 \\
\hline
\end{tabular}
Kadar Kolesterol Total Tikus

Berikut merupakan tabel rerata pengamatan pre dan post pemberian pakan hiperlipidemia pada hari ke 0, 7, 14, 21, dan 28 .

Tabel 1. Rerata kadar kolesterol tikus pada hari ke 0, 7, 14, 21, dan 28.

Berdasarkan tabel di atas, adanya peningkatan kadar kolesterol total pada ke lima kelompok perlakuan selama 28 hari pemberian. Pemberian PTU dapat meningkatkan profil lipid dalam darah lebih cepat jika ditambah pakan tinggi lemak, dan tidak tampak efek yang besar pada kelompok kontrol negatif (tanpa penambahan pakan hiperlipidemia). Adapun peningkatan tersebut, dapat disebabkan karena adanya pemberian pakan hiperlipidemia secara terus menerus pada tikus sehingga mampu mempengaruhi kadar awal kolesterol. Peningkatan yang disebabkan oleh PTU juga 
sejalan dengan penelitian yang dilakukan oleh Posangi, et al. (2012), dimana pemberian PTU dapat menyebabkan terjadinya hipotiroid pada tikus. Pada keadaan hipotiroid terjadi penurunan jumlah reseptor LDL di hati. Hal ini menyebabkan terjadinya peningkatan kadar LDL plasma yang turut meningkatkan kadar kolesterol total.

\section{Pengamatan Pre dan Post Penelitian}

Hasil penelitian diperoleh dari data hasil dua tahap pengukuran kadar kolesterol darah tikus putih jantan yaitu Pre (hari ke-28) dan Post (2 jam setelah pemberian perlakuan pada hari ke-29).

Tabel 2. Perbandingan kadar kolesterol total
tikuS
perlakuan

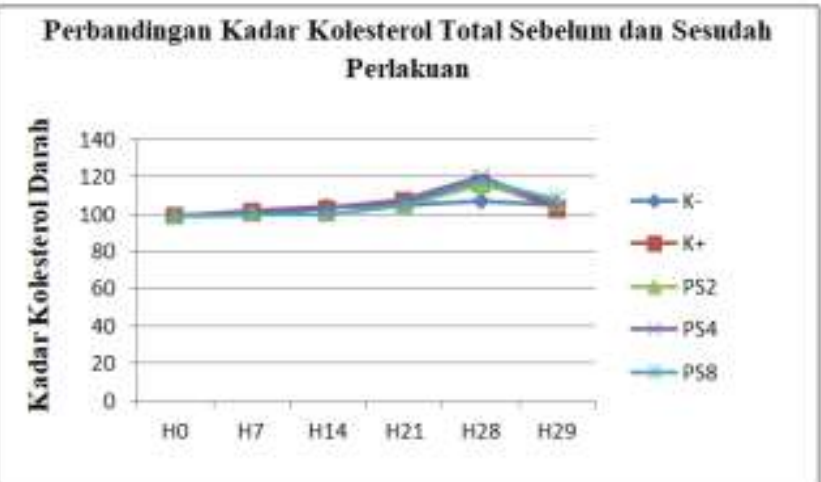

\section{Gambar 1.Grafik perubahan rataan kadar kolesterol darah tiap kelompok perlakuan}

Pada tiap kelompok, dapat dilihat bahwa terjadi penurunan kadar kolesterol sesudah perlakuan. Berdasarkan tabel rerata kadar kolesterol tikus, terlihat bahwa pada hari ke 29, setiap kelompok mengalami penurunan kadar kolesterol dengan angka yang berbeda. Untuk kontrol negatif, walaupun tidak diberi perlakuan tetap mengalami penurunan kolesterol, peneliti berasumsi bahwa penurunan tersebut disebabkan oleh co-inducer (PTU) yang tidak lagi diberikan. Kelompok kontrol positif berfungsi sebagai pembanding. Berdasarkan grafik, penurunan kadar kolesterol $\mathrm{K}+$ berada di angka terendah yaitu $103 \mathrm{mg} / \mathrm{dL}$. Hal ini berkaitan dengan mekanisme kerja dari simvastatin menurut PERKI (2013), dimana simvastatin yang merupakan obat golongan statin yang digunakan untuk menurunkan kadar kolesterol yang paling efektif digunakan. Statin bekerja dengan cara menghambat sintesis kolesterol dalam hati, dengan menghambat enzim HMG-CoA reduktase. Selanjutnya, jika dilihat pada kelompok pemberian ekstrak PS2 (200mg), PS4 (400 mg), dan PS8 (800 mg), masing-masing kelompok menunjukan adanya efek penurunan kadar kolesterol pada tikus. Akan tetapi, nilai rerata penurunan kadar kolesterol total yang paling besar adalah pada kelompok PS4 yaitu menurunkan kadar kolesterol dari $120 \mathrm{mg} / \mathrm{dL}$ menjadi $104 \mathrm{mg} / \mathrm{dL}$.

\section{Aktifitas Farmakologi Kandungan Kimia Buah Pinang Yaki}

Pinang yaki mengandung senyawa tanin, triterpenoida, flavonoid dan saponin yang kemungkinan besar mengandung senyawa potensi bioaktif (Simbala, 2007). Aktivitas ekstrak etanol buah pinang yaki dalam menurunkan kadar kolesterol total, disebabkan oleh adanya kandungan senyawa flavonoid, tannin, dan saponin. Flavonoid dapat 
menurunkan kadar kolesterol total. (Gross, 2004). Senyawa lain dalam buah pinang yaki yang juga diduga berpengaruh pada penurunan kadar kolesterol tikus adalah tanin. Senyawa ini berperan lewat aktivitasnya sebagai antioksidan (Kurniawati, 2015). Tanin dalam buah pinang yaki dimungkinkan juga bekerja dengan mengikat lipid di saluran pencernaan, sehingga mengganggu absorbs lipid di dalam usus, Saponin, pada penelitian terdahulu yang dilakukan oleh Francis et al., (2002), saponin bekerja dengan mengendapkan kolesterol. Mekanisme pengikatan saponin-kolesterol dapat menurunkan kadar trigliserida dengan menghambat pancreatic lipoprotein lipase.

\section{KESIMPULAN}

Berdasarkan hasil dan pembahasan yang telah dijelaskan, maka peneliti menyimpulkan bahwa ekstrak etanol buah pinang yaki memiliki aktivitas antihiperlipidemia. Ekstrak etanol buah pinang yaki (Areca vestiaria) yang memiliki penurunan kadar kolesterol total tikus putih jantan galur wistar (Rattus novergicus L.) terbaik, yakni pada konsentrasi 400 mg (PS4).

\section{SARAN}

Perlu dilakukan penelitian lebih lanjut untuk parameter yang lain, seperti kadar LDL, HDL, dan Trigliserida, serta penelitian terhadap kandungan dari ekstrak buah pinang yaki untuk mengetahui komponen zat aktif yang paling berperan atau berpengaruh pada penurunan kadar kolesterol total.

\section{DAFTAR PUSTAKA}

Anwar, T.B. 2004. Dislipidemia Sebagai Faktor Resiko Penyakit Jantung Koroner [Tesis]. Fakultas Kedokteran Universitas Sumatera Utara, Medan.
Francis, G., Z. Kerem, P.S., Harider. 2002. The Ciological Action Of Saponins in Animal Systems: A Review. British Journal Of Nutriion. (88):587-605.

Gross, Myron. 2004. Flavonoid and Cardiovascular Disease. Pharmaceutical Biology. 21-35.

Kurniawati, A. 2015. Uji Efek Antihiperlipidemia Ekstrak Etanol Buah Parijoto (Medinilla speciosa Blume) Terhadap Kolesterol Total, Trigliserida, dan VLDL pada Tikus Putih Jantan. [Skripsi] UIN Syarif Hidayatullah, Jakarta.

Septianggi,F.N.,Mulyati,T.,Sulistya,H.2013.Hu bungan Asupan Lemak dan Asupan Kolesterol Dengan Kadar Kolesterol Total Pada Penderita Jantung Koroner Rawat Jalan Di RSUD Tugurejo Semarang. Jurnal Gizi Unimu.2(2):1320.

Simbala,H.E.I.2007. Uji Toksisitas dan Uji Pre Klinik Areca vestiaria/Pinang Yaki Sebagai Antifertilitas. Universitas Sam Ratulangi, Manado.

Simbala,H.E.I.2017.Proses Produksi Dan Formulasi Produk Ekstrak Buah Pinang Yaki Areca vestiaria Sebagai Bahan Aktif Produk Fitofarmaka Antikanker. Universitas Sam Ratulangi, Manado.

Suhendra, T.,A, Awaloei, H., Wuisan, J. 2016. Uji Efek Ekstrak Biji Alpukat (Persea americana Mill.) Terhadap Kadar Kolesterol Total pada Tikus Wistar (Rattus norvegicus). Jurnal e-Biomedik (eBm). 4(1) : 1-7.

Yamamoto, M. 2000. Anti Obesity Effects Of Lipase Inhibitor CT-II, An Extract Of Edible Herbs, Nomame Herba, On Rat Fed On A High Fat Diet. International Journal of Obesity. 24(6): 758-764. 


\section{PHARMACON- PROGRAM STUDI FARMASI, FMIPA, UNIVERSITAS SAM RATULANGI,}

Volume 8 Nomor 2 Mei 2019

Perki.2013 Pedoman Tatalaksana Dislipidemia.

Centra Communications, Jakarta.

Posangi, I., J., Posangi, J., Wuisan. 2012. Efek

Ekstrak Daun Sirsak (Annona muricata

L.) Pada Kadar Kolesterol Total Tikus

Wistar. Jurnal Biomedik. 4(1) : 37-42. 